\title{
PREMISAS E PRAXE ÉTICAS DO XORNALISMO
}

\author{
José Videla Rodríguez \\ Universidade da Coruña
}

\section{PREMISAS ÉTICAS DO XORNALISMO}

A ética non está de moda no xornalismo, nin na comunicación en termos xerais, malia as declaracións de principios que se producen cada certo tempo. Non goza da consideración na etapa de formación nin na práctica diaria. En primeiro lugar, nos centros universitarios non se lle dá a importancia que merece para o desenvolvemento profesional; causa verdadeiro desacougo ver como a ética e a deontoloxía profesional carecen de relevancia académica, incluso non forman parte dos plans de estudos, sen que ninguén sexa capaz de dar unha explicación convincente de por que ocorre isto. As empresas non están interesadas en potenciar institucionalmente os valores éticos porque os consideran un atranco da súa actividade tal como a conciben.

Paradoxalmente, as asociacións profesionais e os empresarios semellan amosar interese pola deontoloxía xornalística. É case un rito iniciático que os colexios non oficiais de xornalistas comecen a súa andaina redactando un código deontolóxico. Pola súa parte, moitas empresas teñen recoñecidos códigos de comportamento profesional interno como parte do seu ordenamento laboral. Con todo, tanto nun caso coma noutro, adoitan ser meras declaracións de principios que só serven para fixar con grandes palabras o que se debe facer na praxe xornalística, pero sen efectividade real. Ningún organismo público ou privado se preocupa por ver se se respectan. Nin sequera hai un deses observatorios que tanto abundan para analizar outros aspectos da comunicación social, que avalíe o comportamento ético dos xornalistas e das empresas. E podemos estar seguros que casos para a análise se dan a diario.

A ética xornalística é tan importante para un correcto exercicio profesional como saber redactar unha información. Contra o que sosteñen os que ven na comunicación un oficio de libre acce- 
so sen ningún tipo de regulamentación deontolóxica, a ética caracteriza o profesional en si mesmo e imponlle unha serie de obrigacións ineludibles para unha adecuada práctica. Aínda que pareza unha afirmación radical, un suxeito é bo xornalista se respecta no seu traballo os criterios deontolóxicos. Na medida en que cumpra eses requirimentos actuará como un profesional que busca a veracidade, protexe a liberdade e potencia a súa independencia.

Un dos medios para acadar un mellor nivel ético é a formación específica e universitaria do futuro informador. Desde o momento en que o estudante entra nas aulas universitarias hai que explicarlle a transcendencia da deontoloxía profesional e afondar no coñecemento científico da ética xornalística. É conveniente que se lle explique que na súa conciencia profesional debe estar presente a idea de que ética e calidade informativa van unidas. Non só a utilización das últimas técnicas ou da capacidade de facer unha transmisión inmediata da noticia caracterizan a modernidade informativa; tamén unha correcta aplicación dos principios deontolóxicos é imprescindible para acadar o limiar de calidade xornalística necesaria.

A ética que reclamamos implica comprobar, documentarse, defender e promover a xustiza, a vida e a liberdade, servir os cidadáns, respectar a intimidade, a honra dos protagonistas da información e a presunción de inocencia á hora de facer imputacións. Os xornalistas teñen que ofrecer unha información o máis veraz e obxectiva posible para cumprir correctamente a súa función de mediadores no proceso da comunicación social. En palabras de Luka Brajnovic, hai que promover «aquel xornalismo (...) que dedica unha permanente atención á dinámica dos valores humanos e das forzas sociais, políticas, culturais, etc. (...) forzas que buscan as mellores solucións nos dilemas impostos polo progreso do noso tempo ${ }^{1} \gg$.

A concepción da actividade xornalística que acabamos de describir entra en colisión co xeito de entender o papel dos medios de comunicación e dos xornalistas na actualidade por parte de 
amplos sectores da industria da comunicación. As empresas queren gañar diñeiro nun mercado altamente competitivo, o que produce como consecuencia que o profesional se vexa obrigado en numerosas ocasións a escribir e contar feitos sen seguir as regras de deontoloxía xornalística. Hai que ser o primeiro en contar as noticias ou dar as máis sensacionais para captar máis audiencia. Ante ese obxectivo é habitual saltar os criterios éticos. Ante esta circunstancia é importante que os xornalistas se convertan na primeira barreira contra a desinformación e a manipulación.

\section{A PRAXE DIARIA}

O seguinte paso é aplicar eses coñecementos teóricos á praxe diaria, onde inevitablemente se van producir circunstancias en que o informador terá que resolver conflitos entre o que lle demanda a ética profesional e as presións internas e externas no seu traballo. O marco global que a ética propón confróntase coa práctica diaria nos medios de comunicación. Aí é onde hai que facer efectivas as premisas ás que nos referimos con anterioridade. Como norma xeral debemos dicir que o profesional da comunicación ten que actuar con actitude crítica para coñecer, valorar, interpretar e transmitir os feitos e os acontecementos que poden ser noticia; ten que desenvolver unha praxe crítica que implica investigar e informar buscando a maior obxectividade posible: proporcionar todas as visións dunha noticia, non dar trato de favor a ningunha das partes implicadas e sinalar como probable o que é probable e como certo o que é certo. En definitiva, non alterar a realidade do que honestamente conseguimos coñecer a través do noso traballo.

A actuación profesional correcta conséguese cando o comunicador ten presente o ben común en xeral e o ben do público en particular. A personalidade propia do xornalista radica tamén no seu criterio para discernir a verdade do que ten a aparencia de verdade e para actuar conforme unha correcta conciencia profesional. Isto tradúcese, por exemplo, na presentación das diferentes versións nas informacións contraditorias, empregar comiñas para diferenciar as declaracións dos protagonistas do relato do xornalista e separar coidadosamente os feitos das opinións. 
Todas estas regras poden soar moi primarias. Todos as escoitamos cando estabamos nas facultades. Pero concúlcanse a diario nos medios de comunicación, nos grandes e nos pequenos, nos medios públicos e nos privados, sen reparar en que a correcta utilización dos criterios éticos determina incluso a validez da información. É o que Carlos Soria expresa cando sostén que

o procedemento informativo debe ser susto en si mesmo. Debe facerse honor a unha ética dos procedementos. En caso contrario, aínda que a información como fin ou resultado sexa correcta, se a actuación que se seguiu para a súa obtención non o é, a mensaxe queda eticamente invalidada. Así pois, tanto a mensaxe final como o procedemento teñen que ser correctos en si mesmos ${ }^{2}$.

Seguimos coa relación do que deberiamos facer e non facemos. O xornalista terá que ser honesto e respectuoso consigo mesmo, cos protagonistas da noticia e cos destinatarios da información. Deberá respectar a honra e a intimidade dos demais, de cada persoa, porque a información serve á comunidade, pero tamén afecta a un home individualmente. A honestidade intelectual do informador implica que na súa actividade primará a busca da verdade, discernindo entre a realidade e a aparencia de verdade, sempre fixando como pauta de conduta a obxectividade informativa.

Aínda así debemos ser conscientes de que é utópico pretender dar informacións absolutamente carentes de valoración. A mesma selección de noticias, o lugar e a extensión que ocupan na canle informativa, a descrición dos feitos e a linguaxe que se emprega son eleccións que determinan a morfoloxía da noticia e, en último termo, a forma en que a recibe a audiencia. Por exemplo, a linguaxe e o ton teñen unha especial importancia na comunicación radiofónica porque unha noticia correctamente elaborada adquire un sentido determinado segundo o vocabulario que se empregue e a forma de enunciala do comunicador. En todo caso, 
malia as valoracións inherentes á propia técnica xornalística, o que debe guiar ao profesional é a recta aplicación dos criterios éticos.

O comunicador deberá dar conta do que lle interesa ao público, deixando a un lado as posicións persoais, as actitudes partidistas e rexeitando calquera tipo de presión que afecte á correcta e fiel transmisión da noticia. Os xornalistas están eticamente obrigados polos principios editoriais do medio en que traballan; asumen o compromiso explícito de seguilos ou, cando menos, de non actuar en senso contrario. Este respecto aos principios editoriais non significa someterse á vontade arbitraria da empresa. Os xornalistas deben levalos á práctica e telos presentes con autonomía de criterio.

As actuacións éticas dos xornalistas proxéctanse cara ao público. A audiencia está formada por persoas que non son simples instrumentos para lograr beneficios económicos ou para conseguir o éxito profesional, son suxeitos que merecen respecto profesional e calidade informativa.

A presentación da información como un espectáculo ou a crecente comercialización dos medios de comunicación é un dos perigos máis graves que ten a profesión xornalística. Non xa só polo interese das empresas en aumentar a audiencia ou a tirada co obxecto de facer rendibles as insercións publicitarias, senón pola dinámica que se puxo en marcha nas redaccións de buscar a noticia espectacular ao prezo que sexa, sen importar a forma en que se presenta, sen confirmar as fontes, sen preocuparse do contido e, finalmente, ata sen dicir a verdade ${ }^{3}$.

Os excesos para provocar e chamar a atención proliferan nos medios de comunicación, especialmente nas televisións. Son a consecuencia da preponderante visión comercial da comunicación, que non é mala en si mesma -sen o negocio informativo non habería información plural-, da que participan, por exemplo, os xornalistas que nos seus contratos inclúen o cobro de primas pola

3. Prieto Rodríguez, J.A. «Ética periodística y actividad informativa», en Medios de Comunicación y Autocontrol. Entre la Ética y el Derecho. MAD. Madrid. 1999. P. 129. 
publicidade que xeran os seus programas. Os que así actúan son os primeiros interesados en gañar audiencia sen reparar en criterios, porque esa maior masa de receptores permítelles contar con máis publicidade e, polo tanto, máis ingresos.

Ante feitos como estes, a valoración e aplicación da ética profesional é o mellor instrumento para actuar correctamente. A procura do éxito a calquera prezo provoca unha dinámica que converte a comunicación nun instrumento de deformación da opinión pública. Neste senso é especialmente grave a irresponsabilidade dos comunicadores que desde unha elevada posición profesional conculcan a diario as máis elementais regras de comportamento ético, facendo un uso fraudulento da confianza neles depositada pola audiencia. 


\section{REFERENCIAS BIBLIOGRÁFICAS}

Aznar, Hugo. Comunicación responsable. Deontología y autorregulación de los medios. Ariel. Barcelona. 1999.

Aznar, Hugo. Ética y Periodismo. Códigos, estatutos y otros documentos de autorregulación. Paidós. Barcelona. 1999.

Barroso Asenjo, Porfirio. «Códigos deontológicos de la comunicación», en Diccionario de Ciencias y Técnicas de la Comunicación. Ediciones Paulinas. Madrid. 1991.

Barroso Asenjo, Porfirio. Códigos éticos de la profesión: análisis comparativo. Tomo I. Madrid. 1980.

Barroso Asenjo, Porfirio. «Ética de la Comunicación», en Diccionario de Ciencias y Técnicas de la Comunicación. Ediciones Paulinas. Madrid. 1991.

Barroso Asenjo, Porfirio. «Deontología del emisor», en Diccionario de Ciencias y Técnicas de la Comunicación. Ediciones Paulinas. Madrid. 1991.

Blázquez, Niceto. Ética y Medios de Comunicación. Biblioteca de Autores Cristianos. Madrid. 1994.

Bonete Perales, Enrique. «De la ética filosófica a la deontología periodística», en Éticas de la información y deontologías del Periodismo. Tecnos. Madrid. 1995.

Brajnovic, Luka. Deontología Periodística. $2^{a}$ edición. Eunsa. Pamplona. 1978.

CAmps, Victoria. «El lugar de la ética en los medios de comunicación», en Éticas de la información y deontologías del periodismo. Enrique Bonete Perales, coordinador. Tecnos. Madrid. 1995.

Casasús i Gurí, Josep María. «El Periodismo como comunicación ética», en Comunicación Social. Escola Galega de Administración Pública. Santiago de Compostela. 1994. 
Derieux, Enmanuel. Cuestiones ético-jurídicas de la Información. Eunsa. Pamplona. 1983.

Desantes Guanter, José María. El autocontrol de la actividad informativa. Edicusa. Madrid. 1973.

Desantes Guanter, José María. La verdad en la información. Institución Cultural Simancas. Valladolid. 1976.

EtXeberRía, Xabier. Ética periodística. Cuadernos de Teología de Deusto. Universidad de Deusto. Bilbao. 1995.

FENBY, John. «Nas fronteiras da vida privada: os abusos da prensa sensacionalista, unha ameaza para a liberdade de información», en Correo da Unesco. Outubro 1990.

García Urbaneja, Fernando. «Las éticas de la empresa informativa», en Etica y empresa: una visión multidisciplinar. Fundación Argentaria-Visor. Madrid. 1997.

GonzÁlez Bedoya, Jesús. Manual de Deontología informativa. Alhambra Universidad. Madrid. 1987.

González Gaitano, Norberto. El deber de respeto a la intimidad. Eunsa. Pamplona. 1990.

LAMBETH, Edmund. Un código ético para la profesión. Limusa-Noriega editores. México. 1992.

Petit Caro, Antonio. «Los límites éticos de la información», en Medios de Comunicación. Entre la Ética y el Derecho. Editorial Mad. Madrid. 1999.

Prieto Rodríguez, Juan Antonio. «Ética periodística y actividad informativa», en Medios de Comunicación y autocontrol. Entre la Ética y el derecho. Mad. Madrid. 1999.

SORIA, Carlos. El laberinto informativo: una salida ética. Eunsa. Pamplona. 1997.

SORIA, Carlos. La hora de la ética informativa. Editorial Mitre. Barcelona. 1991. 
SuÁreZ Villegas, Juan Carlos. «Ética y autocontrol profesional», en Medios de comunicación y autocontrol. Entre la Ética y el Derecho. Editorial Mad. Madrid. 1999.

VÁzQUez, Francisco. Ética y Deontología de la Información. Paraninfo. Madrid. 1991.

VÁzQUEZ, Francisco. Fundamentos de Ética Informativa. Forja. Madrid. 1983. 